\title{
AC loss Analysis in Winding of Electrical Machines with varying Strands-in-hand and Bundle Shapes
}

\author{
Anuvav Bardalai, David Gerada, Zeyuan Xu and Chris Gerada \\ Department of Electrical and Electronic Engineering, University of Nottingham, NG7 2RD, U.K.
}

\begin{abstract}
This paper presents an investigation into the sensitivity of high-frequency $\mathrm{AC}$ effects on the winding with varying number of parallel strands. Based on numerical analysis, a methodology to segregate the losses into components is presented. It is shown that the skin and proximity effect losses are not influenced by the shape and the positions of the strand bundles and these losses cannot be neglected for straight conductors even when the strand diameter is less than the skin depth.
\end{abstract}

Index Terms - AC losses, circulating current, skin and proximity losses, winding.

\section{INTRODUCTION}

Governments around the world have introduced stringent emissions stands and international regulations to counter the global challenge of Global Warming [1], [2], and the car manufacturers/ OEMs have chosen to satisfy these targets by incorporating electrical motors with the drivetrains [3]. The targets set by Advanced Proplusion Centre, UK for the year 2025, in the segment of passenger car traction motor are as: $7 \mathrm{~kW} / \mathrm{kg}$ of continuous power density against $2.5 \mathrm{~kW} / \mathrm{kg}$ at current stage, while the cost $(\$ / \mathrm{kW})$ has to reduce by almost half from $10 \$ / \mathrm{kW}$ in current market to $5.8 \$ / \mathrm{kW}$ by 2025 . It has been identified that for lower cost electrical machines, more effective utilisation of existing materials, reducing copper losses through better winding designs, and reducing iron losses are required. As losses in copper windings are one of the major sources of efficiency loss in electrical machines, development has been intensely focused on reducing these losses wherever possible [4].

For traction applications, often low voltage high power density machines combined with low-cost manufacturing are desired. As such, solid straight round magnet wires are employed which offer great potential in ease of manufacturing and overall cost reduction. However, these wires are subjected to high $\mathrm{AC}$ losses in the high frequency region where the machine needs to operate. Therefore, choosing appropriate strand diameter size and bundle shape is of prime importance.

Winding losses in high-speed machines are caused by a combination of the following phenomena [5], [6]: DC copper loss, skin and proximity effects, and circulating current effect caused by uneven current sharing by the strands. This can be expressed as:

$$
P_{\text {Total }}=P_{D C}+P_{\text {skin and proximity }}+P_{\text {circulating current }}
$$

The DC copper loss $\left(I^{2} R\right)$ is the joule loss generated as heat in the strand when a DC current flows through it.
When AC current flows through a strand, it causes the current density near the strand surface to be greater than in the strand core and is known as skin effect. Losses in a strand due to an external imposed field generated by surrounding strands is referred to as proximity effect loss. Proximity effect loss generated in a strand depends on the dimension of the strand, the amplitude and the frequency of the magnetic field where the strand is located [6]. Under loaded conditions, some of the armature field flux leaks inside the slot. Because of the slot flux leakage, each strand of a bundle sees a different flux linkage and thus has a different inductance. This imbalance of inductance between the strands of a bundle in turn results in a circulating current. Circulating current is the main contributing factor for losses in winding of electrical machines with large numbers of strands-in-hand and is well researched [7] - [9].

The purpose of this paper is to investigate the sensitivity of the winding losses with varying number of parallel strands and bundle shape while the slot filling factor is kept approximately constant.

The paper is organised as follows: Section II introduces the machine under investigation and its numerical modelling for AC loss calculation. Section III presents the Finite-Element Analysis (FEA) results. Verification of loss segregation equation is presented in Section IV, and finally in Section V, the conclusions of this research are summerised.

\section{Machine Specification And Methodology}

An existing prototype IPM traction machine, the details of which are listed in TABLE I, is used for the analysis in this paper. The machine has randomly wound concentrated winding, with two coil sides placed sideby-side as shown in the Fig. 1. The maximum slot filling factor achieved is $42 \%$. Here, the slot filling factor is defined as ratio of the copper area and the maximum slot

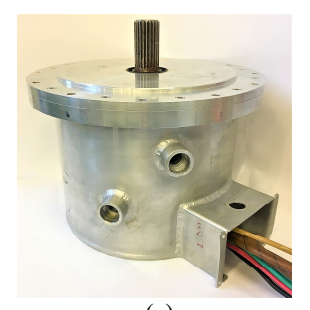

(a)

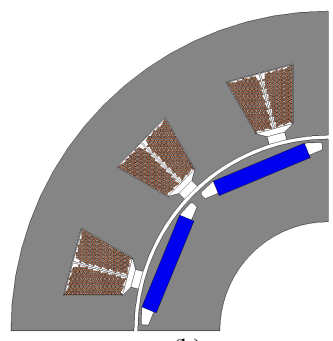

(b)
Fig. 1. (a) The existing machine, (b) Quarter section model of the machine with strand - level winding model. 
TABLE I

MACHINE PARAMETERS

\begin{tabular}{cc}
\hline \hline Parameter & Specification \\
\hline Machine Type & Three - phase PMSM \\
Rotor type & Interior Flat \\
Peak power & $74 \mathrm{~kW}$ \\
Rated torque & $126 \mathrm{Nm}$ \\
Rated / maximum speed & $2800 / 10000 \mathrm{rpm}$ \\
Winding Type & Concentrated \\
Layers & 2 \\
Turns per slot & 20 \\
Strands-in-hand & 33 \\
Slot Filling & $42 \%$ \\
\hline \hline
\end{tabular}

area available for winding (excluding the area for slot opening).

\section{A. Modelling and Strand/bundle arrangements}

For the purpose of this analysis, keeping the conductor area for each turn approximately the same and hence maintaining approximately a similar slot filling factor as the prototype machine, the 'strands-in-hand' is increased in steps from 1 strand per conductor to 33 'strands-inhand'. The models are built at the strand-level and analyses are carried out at an operating point of $10 \mathrm{krpm}$, which translates to fundamental frequency of $666.67 \mathrm{~Hz}$. Due to symmetry, a quarter section of the machine is modelled, and the models are analysed using 2D FEA. Fig 1a shows the actual prototype machine build, Fig. 1b shows the strand-level quarter section model of the machine considered.

Three arrangements of strands and bundles configurations are considered, namely: (a) horizontal (ARR1), (b) vertical bundled (ARR2), and (c) horizontal bundled (ARR3). Fig. 2 shows a slot of the model with the three arrangements. Here, each disc represents a strand. The different coloured discs represent the turns and the discs with same colour represents strands-in-hand of a turn. For example, the models in Fig. 2 have 10 turns represented by 10 different coloured discs and 6 same coloured discs representing the six strands in a turn connected in parallel. This result in 60 strands per coil side in the slot. In the case of horizontal arrangement (ARR1), the strands are laid horizontally across the slot geometry with no constraints on the bundle shape. For the case of vertical bundled arrangement (AAR2), the parallel strands on each turned are bundled and placed along the vertical direction of slot. In addition, in the case

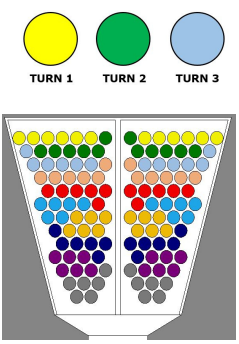

(a)

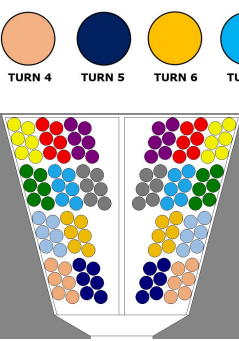

(b)
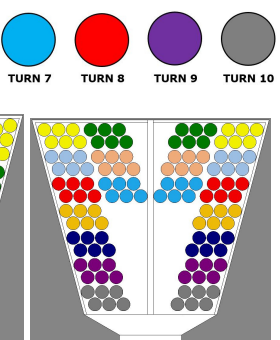

(c)
Fig. 2. The configuration of strands and bundles in the slot as: (a) Horizontal (ARR1), (b) Vertical bundled (ARR2), (c) Horizontal bundled (ARR3)
TABLE II

DIMENSION OF STRANDS USED IN MODELLING

\begin{tabular}{cccc}
\hline \hline $\begin{array}{c}\text { NuMBER OF } \\
\text { PARALLEL } \\
\text { STRANDS }\end{array}$ & $\begin{array}{c}\text { STRAND COPPER } \\
\text { DIAMETER (MM) }\end{array}$ & $\begin{array}{c}\text { TOTAL } \\
\text { STRANDS PER } \\
\text { SLOT }\end{array}$ & $\begin{array}{c}\text { SLOT } \\
\text { FILLING } \\
\text { FACTOR (\%) }\end{array}$ \\
\hline 4 & 1.8 & 80 & $41.70 \%$ \\
6 & 1.5 & 120 & $43.46 \%$ \\
10 & 1.18 & 200 & $44.82 \%$ \\
13 & 1 & 260 & $41.70 \%$ \\
21 & 0.8 & 420 & $43.26 \%$ \\
24 & 0.75 & 480 & $43.46 \%$ \\
33 & 0.63 & 660 & $42.16 \%$ \\
\hline \hline
\end{tabular}

of horizontal bundled arrangement (ARR3), the bundled strands are positioned across the slot geometry. These three cases are selected to represent practical bundling scenarios, where a bundle is shaped along the slot height (ARR2) or across the slot width (ARR3). ARR1 is considered as representation of ideal scenario where the strands are laid in layers.

\section{B. Methodology for eliminating circulating current}

When strands with different inductances are connected in parallel with a sinusoidal source, the current is unevenly shared by the strands and there is a significant difference in the amplitude and phase of the current in each strand. In order to eliminate the effect of circulating current at the simulation level, each strand is supplied with its own current source to distribute the supply current equally among the parallel strands. Supplying each strand with its individual source eradicate the effects from slot leakage flux and thus the circulating current at the simulation level. Fig. 3 shows the circuital representation of the strands and bundle connections in the models with (a) a single source supply and (b) with supply source connected to each individual strand (multisource supply). In the case of multi - source supply, the main current is equally divided among the individual sources and thus resulting in the elimination of the losses caused by the circulating current effect.

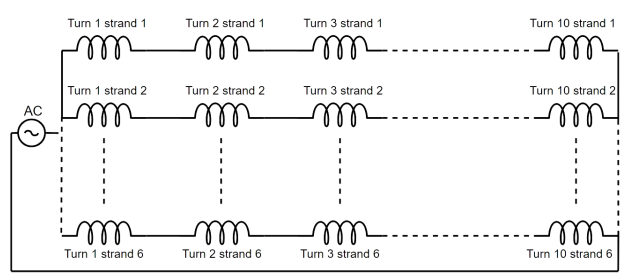

(a) Single supply source

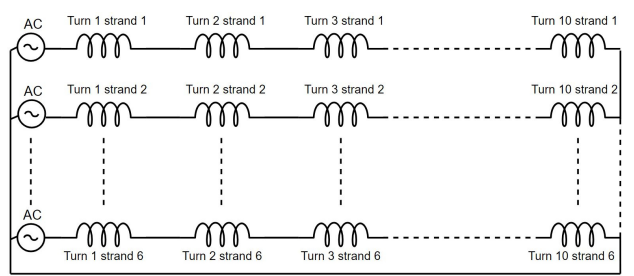

(b) Multiple supply sources, each connected to individual strand

Fig. 3. Circuital representation of the strands and bundle connections in the models 


\section{Simulation Results}

\section{A. Horizontal Arrangement (ARR1)}

For ARR1, the strands and bundles layout are as shown in Fig. 2a. TABLE II lists the dimensions of the strands used in this analysis along with the other relevant details.

Fig. 4 shows the losses in the individual conductors for the models with varied number of parallel strands. As the conductors' position moves closer to the slot top (towards slot opening, where flux leakage is higher), the conductors exhibit larger losses than the ones place towards the slot bottom. That is, the losses in individual conductors increase from conductor 1 to conductor 10 for ARR1. This is true for all the models. In addition, the trend in Fig. 4 suggests that as the number of parallel strands forming a conductor increase, the difference in the losses in the conductors placed at the slot top and slot bottom gradually decreases. This is evident from Fig. 4, where there is a $162.74 \%$ increase in the losses in conductor 10 as to the losses in conductor 1 for model with 4 parallel strands, whereas in case of the model with 33 parallel strands, the increase in the losses in conductor 10 to the losses in conductor 1 is $16.64 \%$. TABLE III lists the total loss in the winding of machine and the $(\mathrm{AC}+\mathrm{DC}) / \mathrm{DC}$ loss ratio for the models with varied parallel strands. The DC ohmic loss in the winding of the models in $412 \mathrm{~W}$. The skin depth at the fundamental frequency of $666.67 \mathrm{~Hz}$ is calculated to be $2.59 \mathrm{~mm}$, which is larger than the diameters of strands used in the models (as listed in TABLE II).

Following the methodology described in sub-section II-B., the effects of circulating currents are eliminated and the losses for the models with and without the

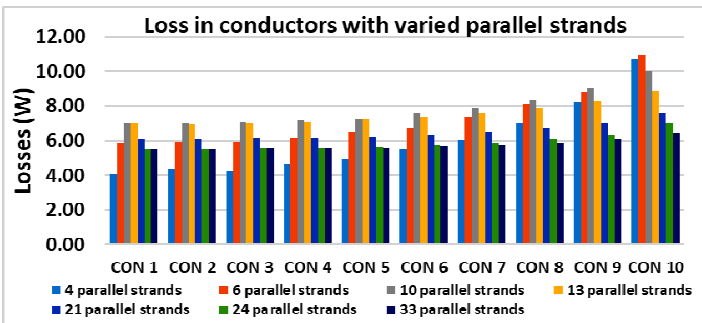

Fig. 4. Losses in individual conductors with varied number of parallel strands

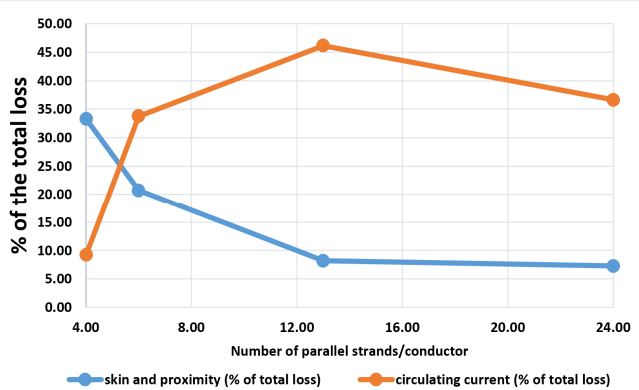

Fig. 5. Trend of skin \& proximity losses and circulating current losses with increasing number of parallel strands.
TABLE III

LOSSES IN MODELS WITH VARIED PARALLEL STRANDS (ARR1)

\begin{tabular}{ccc}
\hline \hline $\begin{array}{c}\text { MODEL WITH } \\
\text { PARALLEL STRANDS }\end{array}$ & $\begin{array}{c}\text { TOTAL WindiNG Loss IN } \\
\text { MACHINE (W) }\end{array}$ & $\begin{array}{c}\text { (AC+DC) / DC } \\
\text { LOSS }\end{array}$ \\
\hline 4 & 716.92 & 1.74 \\
6 & 867.36 & 2.20 \\
10 & 939.33 & 2.45 \\
13 & 902.75 & 2.20 \\
21 & 776.96 & 2.05 \\
24 & 704.52 & 1.78 \\
33 & 689.89 & 1.75 \\
\hline \hline
\end{tabular}

TABLE IV

COMPARISON OF MODELS WITH AND WITHOUT CIR. CURRENT (ARR1)

\begin{tabular}{|c|c|c|c|c|}
\hline \multirow{2}{*}{$\begin{array}{l}\text { MODELS } \\
\text { WITH } \\
\text { ARALLEL } \\
\text { TRANDS }\end{array}$} & \multicolumn{2}{|c|}{$\begin{array}{l}\text { TOTAL LOSS IN THE WINDING } \\
\text { (W) }\end{array}$} & \multicolumn{2}{|c|}{$(\mathrm{AC}+\mathrm{DC}) / \mathrm{DC}$ LOSS } \\
\hline & $\begin{array}{c}\text { WITH } \\
\text { CIRCULATING } \\
\text { CURRENT }\end{array}$ & $\begin{array}{c}\text { WITHOUT } \\
\text { CIRCULATING } \\
\text { CURRENT }\end{array}$ & $\begin{array}{c}\text { WITH } \\
\text { CIRCULATING } \\
\text { CURRENT }\end{array}$ & $\begin{array}{l}\text { WITHOUT } \\
\text { CIRCULATIN } \\
\text { CURRENT }\end{array}$ \\
\hline 4 & 716.92 & 651.54 & 1.74 & 1.58 \\
\hline 6 & 867.36 & 574.93 & 2.196 & 1.455 \\
\hline 13 & 902.75 & 485.65 & 2.2 & 1.18 \\
\hline 24 & 704.52 & 445.06 & 1.78 & 1.13 \\
\hline
\end{tabular}

circulating currents along with the loss ratio are listed in TABLE IV. When the circulating currents in the models are eliminated, the losses gradually drop from the model with least number of parallel strands (4 parallel strands) to the model with the highest number of parallel strands (24 parallel strands) in TABLE IV. From the trend of the losses shown in Fig. 5, it is evident that with increase in the number of the 'strands-in-hand', while the contribution by the skin and proximity effects decrease, the contribution from the circulating currents increase. This confirm why for ARR1, the total losses for models with $6,10,13$ and 21 parallel strands are high, as compared with the model with fewer number of parallel strands (4 parallel strands) and with higher number of

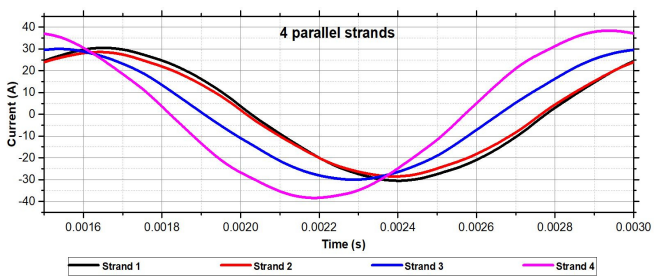

(a)

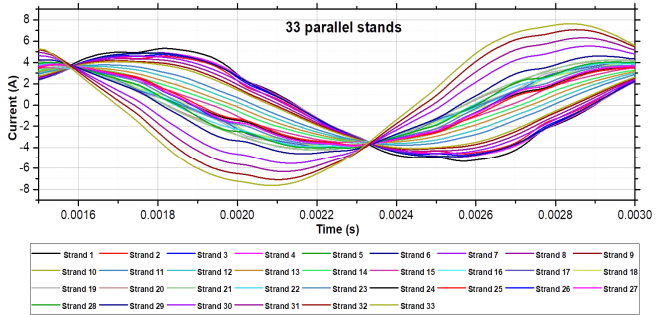

(b)

Fig. 6. (a) Waveforms of individual strand currents with 4 parallel strands model, (b) Waveforms of individual strand currents with 33 parallel strands model. 
parallel strands. That is, the combination of higher skin and proximity effects and the circulating current for models with $6,10,13$ and 21 parallel strands cause the total losses in the winding to increase. Fig. $6 \mathrm{~b}$ and $6 \mathrm{c}$ shows the current in the individual strands for the 4 parallel strands and 33 parallel strands models respectively. Due to circulating current effect, the main current (reference) is unevenly shared by the parallel strands and the individual strand current waveforms are displaced in time when compared to the reference current waveform. With increase in the number of 'strands-inhand', the individual strands occupy different positions (across slot height and width) within the slot geometry. The individual strands link varying flux in the slot and see a different impedance which cause the circulating current to increase and unbalanced current sharing occurs.

Referring to TABLE II, both the 4 and 13 parallel strands models have a slot filling factor of $41.7 \%$. Comparing both models following the elimination of the circulating currents, the skin and proximity effects add $58 \%$ excess loss to the DC loss in case of 4 parallel strands model, while the excess loss by skin and proximity effects in case of 13 parallel strands model is $18 \%$ over the DC loss value. The comparison of the breakdown of the losses in the winding for both these models is shown in Fig. 7a.

Similarly, both the 6 and 24 parallel strands models have a slot filling factor of $43.46 \%$. Comparing both the models, following the elimination of circulating currents, the excessive loss added by the skin and proximity effects is $45.5 \%$ over the DC loss value in the case of 6 parallel strands model and $13 \%$ for the model with 24 parallel strands. The breakdown of the losses in the winding are presented in Fig. $7 \mathrm{~b}$.

\section{B. Vertical Bundled (ARR2)}

The models with parallel strands: $6,10,13$ and 24 are considered for the vertical bundled configuration (ARR2). Fig. 8 shows the 6 and 24 parallel strands models.

TABLE $\mathrm{V}$ lists the losses in the winding and the loss ratio for models with ARR2 configurations. As with subsection III-A, TABLE VI presents the losses and the

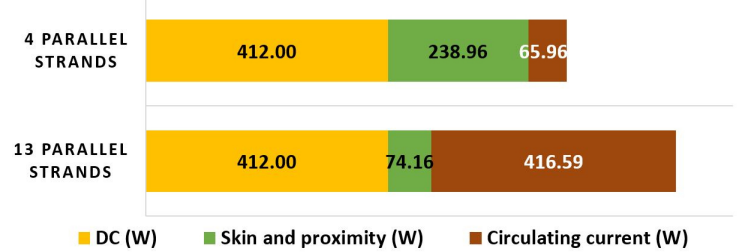

(a) 4 and 13 parallel strands models

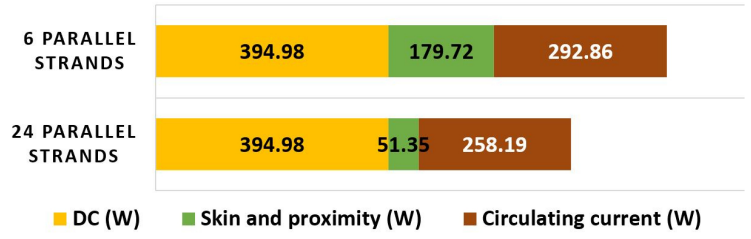

(b) 6 and 24 parallel strands models

Fig. 7. Comparison of breakup of the losses in the winding.
TABLE V

LOSSES IN MODELS WITH VARIED PARALLEL STRANDS (ARR2)

\begin{tabular}{ccc}
\hline \hline $\begin{array}{c}\text { Model WiTH } \\
\text { PARALLEL STRANDS }\end{array}$ & $\begin{array}{c}\text { TotAl Winding Loss IN } \\
\text { MACHINE (W) }\end{array}$ & $\begin{array}{c}\text { (AC+DC)/DC } \\
\text { LOSS }\end{array}$ \\
\hline 6 & 1737.82 & 4.4 \\
10 & 2219.48 & 5.8 \\
13 & 1629.96 & 3.97 \\
24 & 2289.43 & 5.8 \\
\hline \hline
\end{tabular}

TABLE VI

COMPARISON OF MODELS WITH AND WITHOUT CIRCULATING CURRENT (ARR2)

\begin{tabular}{|c|c|c|c|c|}
\hline \multirow{2}{*}{$\begin{array}{l}\text { MODELS } \\
\text { WITH } \\
\text { PARALLEL } \\
\text { STRANDS }\end{array}$} & \multicolumn{2}{|c|}{$\begin{array}{l}\text { TOTAL LOSS IN THE } \\
\text { WINDING }(\mathrm{W})\end{array}$} & \multicolumn{2}{|c|}{$\begin{array}{c}(\mathrm{AC}+\mathrm{DC}) / \mathrm{DC} \\
\mathrm{LOSS}\end{array}$} \\
\hline & $\begin{array}{l}\text { WITH CIR. } \\
\text { CURRENT }\end{array}$ & $\begin{array}{c}\text { WITHOUT } \\
\text { CIR. } \\
\text { CURRENT }\end{array}$ & $\begin{array}{l}\text { WITH CIR. } \\
\text { CURRENT }\end{array}$ & $\begin{array}{c}\text { WITHOUT } \\
\text { CIR. } \\
\text { CURRENT }\end{array}$ \\
\hline 6 & 1737.83 & 574.45 & 4.4 & 1.45 \\
\hline 24 & 2289.43 & 444.15 & 5.8 & 1.12 \\
\hline
\end{tabular}

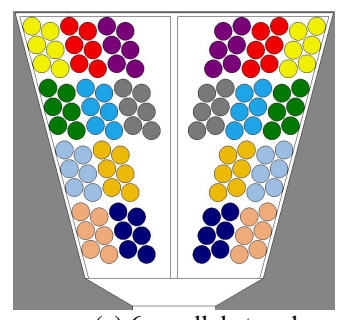

(a) 6 parallel strands

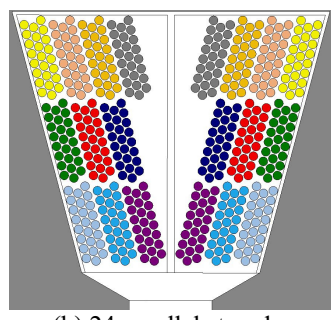

(b) 24 parallel strands
Fig. 8. Models with vertical bundled strands arrangements (ARR2).

loss ratio with and without the circulating currents for the 6 and 24 parallel strands models with ARR2. By eliminating the effects due to the circulating currents, the total losses in the winding drops by $67 \%$ for the 6 parallel strands model and by $80.6 \%$ in case of the 24 parallel strands model.

Fig. 9 shows the three - phase sinusoidal waveform of the current source. To put further insight into the significant increase in circulating current losses, Fig. 10 and Fig. 11 circulating currents for the model with 6 and 24 parallel strands (ARR2) respectively. At the time instant $0.00194 \mathrm{~s}$ (marked by the dashed line in Fig. 9), the current in phase A connected to coil 1 in both the 6 and 24-strand models shown in Fig. 10 and Fig. 11 is zero, while the remaining two phases have some amplitude. The circulating current caused by the slot flux leakage in the bundles of coil 1 can be clearly observed in Fig. 10a. These circulating currents are eliminated when each strand is supplied with its individual current source.

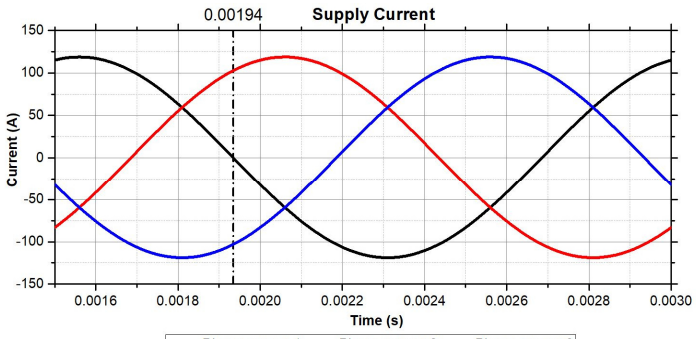
- Phase current 1 - Phase current 2 — Phase current 3

Fig. 9. Sinusoidal waveform of three phase supply current with marked time at $0.00194 \mathrm{~s}$ 


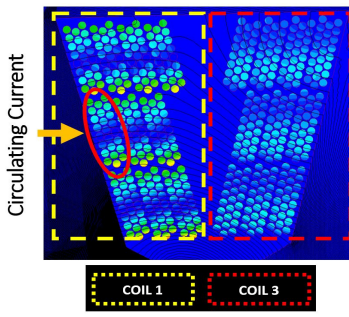

(a) with circulating current

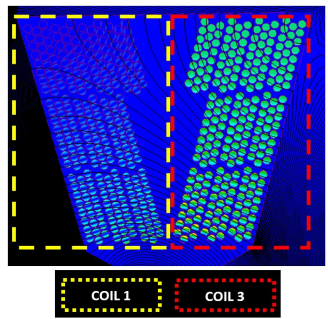

(b) without circulating current
Fig. 10. Comparison of current density $(\mathrm{J})$ in the strands for the 24 parallel strands models (ARR2) at time instant $(0.00194 \mathrm{~s})$

\begin{tabular}{|c|c|c|c|c|}
\hline \multicolumn{5}{|c|}{$\begin{array}{l}\text { TABLE VII } \\
\text { COMPARISON OF MODELS WITH AND WITH }\end{array}$} \\
\hline \multirow{2}{*}{$\begin{array}{l}\text { MODELS } \\
\text { WITH } \\
\text { PARALLEL } \\
\text { STRANDS }\end{array}$} & \multicolumn{2}{|c|}{$\begin{array}{l}\text { TOTAL LOSS IN THE } \\
\text { WINDING }(\mathrm{W})\end{array}$} & \multicolumn{2}{|c|}{$\begin{array}{c}(\mathrm{AC}+\mathrm{DC}) / \mathrm{DC} \\
\text { LOSS }\end{array}$} \\
\hline & $\begin{array}{l}\text { WITH CIR. } \\
\text { CURRENT }\end{array}$ & $\begin{array}{c}\text { WITHOUT } \\
\text { CIR. } \\
\text { CURRENT }\end{array}$ & $\begin{array}{l}\text { WITH CIR. } \\
\text { CURRENT }\end{array}$ & $\begin{array}{c}\text { WITHOUT } \\
\text { CIR. } \\
\text { CURRENT }\end{array}$ \\
\hline 6 & 1188.7 & 576.42 & 3.01 & 1.46 \\
\hline
\end{tabular}

\section{Horizontal Bundled (ARR3)}

For the ARR3 configuration, only the model with 6 parallel strands shown Fig. 2c is considered. The circulating current effect in the models with a lower number of parallel strands is insignificant and because of slot geometry constraints, models with higher number of parallel strands in ARR3 configuration with constrained bundle shape are not feasible.

TABLE VII lists the losses in the winding and the loss ratio for the model with 6 parallel strands for the ARR3 configuration.

\section{Comparison of segregated loss components in the three configurations}

For this comparison, the 6 parallel strands model across all three configurations (ARR1, ARR2, ARR3) is considered. The three configurations with 6 parallel strands are shown in Fig. 2. Fig. 11 shows the comparison of the segregated loss components in all three configurations.

Let,

$$
\begin{aligned}
P_{\text {skin and proximity }} & =P_{S P} \\
P_{\text {ciculatiing current }} & =P_{c c}
\end{aligned}
$$

Dividing both sides of eq. (1) by $P_{D C}$, we get

$$
\frac{P_{\text {Total }}}{P_{D C}}=\frac{P_{D C}}{P_{D C}}+\frac{P_{S P}}{P_{D C}}+\frac{P_{c c}}{P_{D C}}
$$

Therefore, the ratio of each loss component in the strands to the DC loss for the three arrangements can be listed as in TABLE VIII. In this table, the skin and proximity effects losses in the strands do not really depend on the shape and position of the bundles, as these losses for all the three strands/bundles configurations (ARR1, ARR2 and ARR3) are approximately the same. However, the circulating current losses are very sensitive
TABLE VIII

COMPARISON OF SEGREGATED LOSS COMPONENTS TO DC LOSS RATIO FOR THE THREE CONFIGURATIONS (6 PARALLEL STRANDS MODEL)

\begin{tabular}{cccc}
\hline \hline PARAMETER & ARR1 & ARR2 & ARR3 \\
\hline$(A C+D C) / D C$ & 2.196 & 4.4 & 3.01 \\
$P_{D C} / P_{D C}$ & 1 & 1 & 1 \\
$P_{S P} / P_{D C}$ & 0.456 & 0.45 & 0.46 \\
$P_{c c} / P_{D C}$ & 0.74 & 2.96 & 1.56 \\
\hline \hline
\end{tabular}

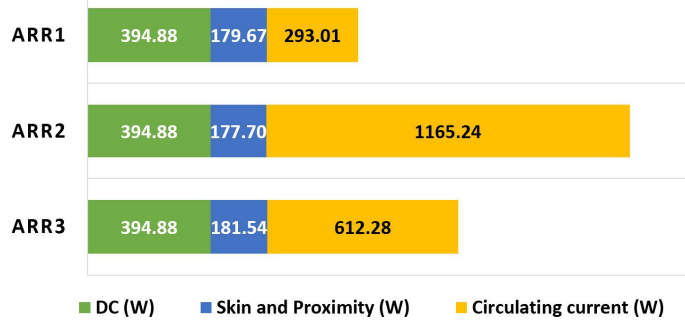

Fig. 11. Segregation of losses in the winding into components for ARR1, ARR2 and ARR3

to the bundle shape and careful consideration should be made in laying the bundled conductors in the slot. The comparison shows that the ARR1 causes the least increase of $\mathrm{AC}$ effects in the winding, followed by ARR3 and the worst configuration is ARR2. Although, the ARR1 would be ideal for lower loss in winding of the machine, in practice, arranging the winding of a random wound machine as ARR1 is impractical. In case of ARR3, the losses are comparatively smaller than ARR2. However, it does not provide flexibility in terms of configuring the bundles in the given slot geometry. Therefore, a trade - off between all three strands/bundles configurations with the least loss would be an optimal solution where the strands are arranged as such that the variation of flux linkage between them is at minimum.

\section{VERIFICATION OF EQUATION}

In the introduction section equation (1) was introduced. According to authors in [10] if skin and proximity effect losses are neglected, the circulating current losses $P_{c c}$, can be approximated as :

$$
P_{c c} \approx P_{\text {Total }}-P_{D C}
$$

TABLE IX

\begin{tabular}{ccccc}
\multicolumn{5}{c}{ VERIFICATION OF EQUATION USING MODELS } \\
$\begin{array}{c}\text { MoDELS } \\
\text { WITH }\end{array}$ & $\begin{array}{l}P_{\text {Total }} \\
\text { PARALLEL }\end{array}$ & $k_{c c}$ & $\frac{P_{S P}}{P_{D C}}$ & $\frac{P_{S P}}{P_{D C}}$ \\
STRANDS & $D$ & & (CALCULATED) & $\begin{array}{c}\text { (MULTI- } \\
\text { SOURCE) }\end{array}$ \\
\hline 4 (ARR1) & 1.74 & 1.175 & 0.565 & 0.58 \\
6 (ARR1) & 2.196 & 1.4 & 0.456 & 0.455 \\
13(ARR1) & 2.2 & 2.024 & 0.176 & 0.18 \\
24(ARR1) & 1.78 & 1.66 & 0.12 & 0.13 \\
6 (ARR2) & 4.4 & 3.96 & 0.44 & 0.45 \\
24 (ARR2) & 5.8 & 4.67 & 0.13 & 0.13 \\
\hline \hline
\end{tabular}


The circulating current loss factor, $k_{c c}$, is a practical indicator of the circulating current losses and is the ratio between $P_{\text {Total }}$ and $P_{D C}$, i.e. it is equal to the loss produced in the case where circulatory current exists relative to the situation where the sum of the current is equally divided between the strands.

The loss factor, $k_{c c}$ can be obtained as:

$$
k_{c c}=N_{p} \frac{\sum_{n=1}^{N_{p}}\left|\frac{i}{n}\right|^{2}}{\left|\sum_{n=1}^{N} \frac{i}{n}\right|^{2}}=\frac{P_{\text {Total }}}{P_{D C}}=\frac{P_{c c}+P_{D C}}{P_{D C}}
$$

Where, $N_{p}$ is the number of parallel strands and $\underline{i}_{n}$ is the complex value of current in strand $n$.

Considering the 6 parallel strand model with ARR2 configuration (vertical bundled), since the strand diameter is less than the skin depth at the fundamental frequency, the skin and proximity effect losses are assumed to be mitigated and thus can be neglected. Therefore, using equation (4) for the model $k_{c c}=3.96$ is obtained. In the absence of skin and proximity effect the value of $k_{c c}$ should be same as $P_{\text {Total }} / P_{D C}$ from equation (3). However, for this model, it has been shown in TABLE VI, that $P_{\text {Total }} / P_{D C}=4.4$.

From equation (4),

$$
\frac{P_{c c}}{P_{D C}}=k_{c c}-\frac{P_{D C}}{P_{D C}}
$$

Using equation (5) in equation (2) for this model:

$$
\frac{P_{S P}}{P_{D C}}=\frac{P_{T o t a l}}{P_{D C}}-\frac{P_{D C}}{P_{D C}}-\frac{P_{c c}}{P_{D C}}=0.44
$$

Now, from the multi - source model, where there is no circulating current, we have, $P_{\text {Total }} / P_{D C}=1.45$. With no circulating current equation (2) can be re-written as

$$
\frac{P_{\text {Total }}}{P_{D C}}=\frac{P_{D C}}{P_{D C}}-\frac{P_{S P}}{P_{D C}} \quad, P_{c c}=0
$$

Therefore, $P_{S P} / P_{D C}=0.45$. This is practically equal to the value obtained by equation (6). Repeating the above calculation procedure for the other models, the list in TABLE IX is obtained.

For all the models considered for verification in TABLE IX, the value of obtained from equation (6) and the value obtained from equation (7) are almost equal.

\section{CONCLUSION}

In this paper, the sensitivity of $\mathrm{AC}$ losses in the winding with varying strand numbers and bundle shapes were analysed in depth on an existing prototype traction machine. A methodology to segregate the total loss in the winding into components was described. It is shown that even when the strand diameter is smaller than the skin depth, skin and proximity effects exist, and cannot be neglected for winding with straight conductors. Furthermore, the skin and proximity effects are largely independent of the bundle shape and position, while the phenomenon of circulating current is very sensitive and is significantly affected by the shape of the bundle. Using the loss segregation methodology on various models, it is verified that the total loss in the winding can be split into components and that the loss segregation equation holds true.

\section{REFERENCES}

[1] "Global Energy \& $\mathrm{CO}_{2} 2$ Status Report 2017," International Energy Agency, March 2018, Available: https://www.iea.org/publications/freepublications/publicati on/GECO2017.pdf.

[2] "A technical summary of Euro 6/VI vehicle emission standards," icct, ed, 2016, Available: https://www.theicct.org/sites/default/files/publications/ICC T_Euro6-VI_briefing_june2016.pdf

[3] M. Popescu, J. Goss, D. A. Staton, D. Hawkins, Y. C. Chong, and A. Boglietti, "Electrical Vehicles-Practical Solutions for Power Traction Motor Systems," IEEE Transactions on Industry Applications, vol. 54, no. 3, pp. 2751-2762, May 2018.

[4] U. K. Advanced Propulsion Centre, "THE ROADMAP REPORT, Towards 2040: A Guide to Automative Propulsion Technologies, Available: https://www.apcuk.co.uk/app/uploads/2018/06/roadmapreport-26-6-18.pdf," ed, 2018.

[5] D. Bauer, P. Mamuschkin, H. Reuss, and E. Nolle, "Influence of parallel wire placement on the AC copper losses in electrical machines," in 2015 IEEE International Electric Machines Drives Conference (IEMDC), 2015, pp. 1247-1253.

[6] S. Iwasaki, R. P. Deodhar, Y. Liu, A. Pride, Z. Q. Zhu, and J. J. Bremner, "Influence of PWM on the Proximity Loss in Permanent-Magnet Brushless AC Machines," IEEE Transactions on Industry Applications, vol. 45, no. 4, pp. 1359-1367, 2009.

[7] M. Popescu and D. G. Dorrell, "Proximity Losses in the Windings of High Speed Brushless Permanent Magnet AC Motors With Single Tooth Windings and Parallel Paths," IEEE Transactions on Magnetics, vol. 49, no. 7, pp. 39133916, 2013.

[8] M. Vetuschi and F. Cupertino, "Minimization of Proximity Losses in Electrical Machines With Tooth-Wound Coils," IEEE Transactions on Industry Applications, vol. 51, no. 4, pp. 3068-3076, July 2015.

[9] A. Bardalai et al., "Reduction of Winding AC Losses by Accurate Conductor Placement in High Frequency Electrical Machines," in IEEE Transactions on Industry Applications, vol. 56, no. 1, pp. 183-193, Jan.-Feb. 2020, doi: 10.1109/TIA.2019.2947552.

[10] A. Lehikoinen, N. Chiodetto, E. Lantto, A. Arkkio, and A. Belahcen, "Monte Carlo Analysis of Circulating Currents in Random-Wound Electrical Machines," IEEE Transactions on Magnetics, vol. 52, no. 8, pp. 1-12, 2016. 